\title{
Sound Financial Management and Happiness: Economic Pressure and Relationship Satisfaction as Mediators
}

\author{
Bryan K. Spuhlera ${ }^{\infty}$ and Jeffrey Dew ${ }^{b} \odot$
}

This study examines the relationship between sound financial management behaviors and happiness using a national sample of adults collected in $2009(N=1,014)$. We used Maslow's hierarchy of needs (1943) as a theoretical framework to examine associations between sound financial management behavior, economic pressure, relationship satisfaction, and happiness. Findings suggested that economic pressure and relationship satisfaction both mediated the association between sound financial management and happiness, but the mediator effects were only partial. That is, even after accounting for participants' actual financial context, feelings of economic pressure, and relationship satisfaction, a positive association between sound financial management behavior and happiness remained.

Keywords: sound financial management behavior, economic pressure, relationship satisfaction, happiness

A lthough empirical studies have suggested that money might be able to "buy happiness" (Stevenson \& Wolfers, 2013), the use to which individuals put their income may more strongly relate to happiness than income itself. Individuals who have the same level of income, but who use it differently may have different levels of happiness. For example, one individual who saved some of their income might be happier than another individual who had the same income, but used all of it for conspicuous consumption purposes.

Unfortunately, not many studies have tested the financial planning maxim that asserts where money is spent is more important than how much one makes. Although a few studies have examined the association between sound financial management and happiness (e.g., Shim, Xiao, Barber, \& Lyons, 2009; Xiao, Tang, \& Shim, 2009), most of these studies have been limited to college students and few have used national data. Using Maslow's hierarchy of needs (1943), we create and test a model of the association between sound financial management behaviors and happiness (see also Lee \& Hanna, 2015). Specifically, we test a model that ties sound financial management to happiness through individuals' reports of meeting basic needs-feelings of safety and of love and belonging. In doing this, our purpose is to examine whether participation in sound financial management behaviors satisfied these two levels of Maslow's hierarchy of needs and were associated with higher levels of happiness. Given that the products of sound financial management (e.g., savings/consumer debt) have been associated with feelings of anxiety (Drentea, 2000), and relationship wellbeing (e.g., Dew, 2007), we suspect that sound financial management helps individuals meet basic needs such as feelings of security and of love/belonging, which then improves their happiness.

Testing this model is important for a few reasons. Such a test assesses the adage that it is not how much income individuals have, but what they do with their income that matters. Not many studies have examined the impact of participating in sound financial behaviors on happiness. Knowing that sound financial management enhances happiness, even after accounting for individuals' financial situation, would be an idea that financial professionals could use to help motivate their clients. Further, this model tests links through which sound financial management might be associated with greater happiness. It tests potential mechanisms through which sound financial management might

\footnotetext{
${ }^{a}$ Assistant Professor, Child and Family Sciences, University of Southern Mississippi, 118 College Dr. \#5035, Hattiesburg, MS 39406. E-mail: bryan.spuhler@usm.edu

${ }^{b}$ Associate Professor, School of Family Life, Brigham Young University, Joseph F. Smith Building Rm 2806, Provo, UT 84602. E-mail: jeff_dew@byu.edu
} 
do more than just enhance individuals' financial bottom lines. Finally, it applies a widely used and understood model of happiness (i.e., Maslow's hierarchy of needs [1943]), to financial matters. This is helpful because it can guide future research. If sound financial management behaviors are indeed linked to happiness, and if participants' feelings of financial security and relationship satisfaction fully mediate the association, then researchers and practitioners would know that these are the main pathways. If full mediation does not occur-a strong possibility given our theoryresearchers could investigate additional mechanisms offered through the Maslow's hierarchy. We used a national sample of adults $(N=1,014)$ to test our hypotheses.

\section{Literature Review}

Happiness is a lay term for the construct that is often referred to as subjective well-being in the literature (Diener, Oishi, $\&$ Lucas, 2003). Subjective well-being is a complex construct which, while often measured as a single-item variable, can be influenced by many factors (Kahneman, Diener, \& Schwarz, 1999). Given that participants in our study responded to a question about their well-being using different levels of "happiness" we will use the term happiness to describe our main dependent variable.

We define sound financial management behaviors as those behaviors which allow individuals to maintain control of their finances and build greater wealth. Some of these behaviors are basic, such as using a budget or spending plan and tracking income and expenditures (Davis \& Weber, 1990). Managing credit is also an important sound financial behavior because, although credit can help households smooth consumption during difficult periods, consumer credit's high interest rates make it a less appropriate long-term solution for many families (Baek \& DeVaney, 2010). Furthermore, used as a way to boost consumption beyond one's income, consumer credit can become a financially draining problem. As an alternative to consumer credit, saving and investing can also help households smooth consumption during periods of difficulty (Baek \& DeVaney, 2010). Savings and investments also allow households to save for future goals, such as a down payment on a house or for retirement. Financial assets also give families more control over their own financial and general futures and provide noneconomic benefits (Sherraden, 1991; Sherraden, McBride, \& Beverly, 2010). Finally, individuals purchase insurance to transfer the financial risk of catastrophic accident. In other words, insurance protects individuals' and families' income and assets.

\section{Sound Financial Management Behaviors and Maslow's Hierarchy}

We use Maslow's hierarchy of needs (1943) as the framework for a model that links savings behaviors and happiness (see Figure 1). Maslow asserted that a hierarchy of needs motivated much, though not all, of human behavior. These basic needs, in order, are: physiological needs (e.g., food, water, etc.), safety and security needs (e.g., the physical safety of one's person), love/belonging needs (e.g., feeling loved by others), esteem needs (e.g., self-respect and esteem from others), and self-actualization needs (e.g., the ability reach one's potential). These needs build on each other such that when an individual satisfies one need, they gradually begin to feel the next need in the hierarchy. That is, after one meets their basic physiological needs of food, water, and shelter, they begin to feel the need for more general safety. A common misconception about Maslow's hierarchy is the notion that a lower need must be met or fulfilled before a higher need can motivate behavior. Although Maslow's earlier works suggested this, his later work (1971) clarified that different levels of need may concurrently motivate behavior, but lower levels tend to be more dominant over higher levels until they are fulfilled (Maslow, 1971).

Needs motivate individuals' behaviors in an attempt to satisfy them. This idea, then, raises the question of whether Maslow's basic needs motivate sound financial management behaviors. Multiple studies suggests that needs may motivate at least savings behaviors. Xiao and Noring's (1994) analysis noted that reported savings motivation differed based on household characteristics and that those motivations reflected multiple and often hierarchical needs as Maslow's framework would imply. In their analysis, Lee and Hanna (2015) evaluated the Survey of Consumer Finance participants' reasons for savings and found that many of these reasons lined up with Maslow's hierarchy. For example, some participants asserted that they saved for daily expenses, which would line up neatly with meeting physiological needs, whereas others stated that they saved for unexpected emergencies, which may line up with the safety need. The majority of participants said that they saved for safety/security and love/family needs, but participants' responses did represent all five of the basic needs (Lee \& Hanna, 2015). 
Figure 1. Conceptual framework linking sound financial management behavior to happiness using Maslow's hierarchy of needs.

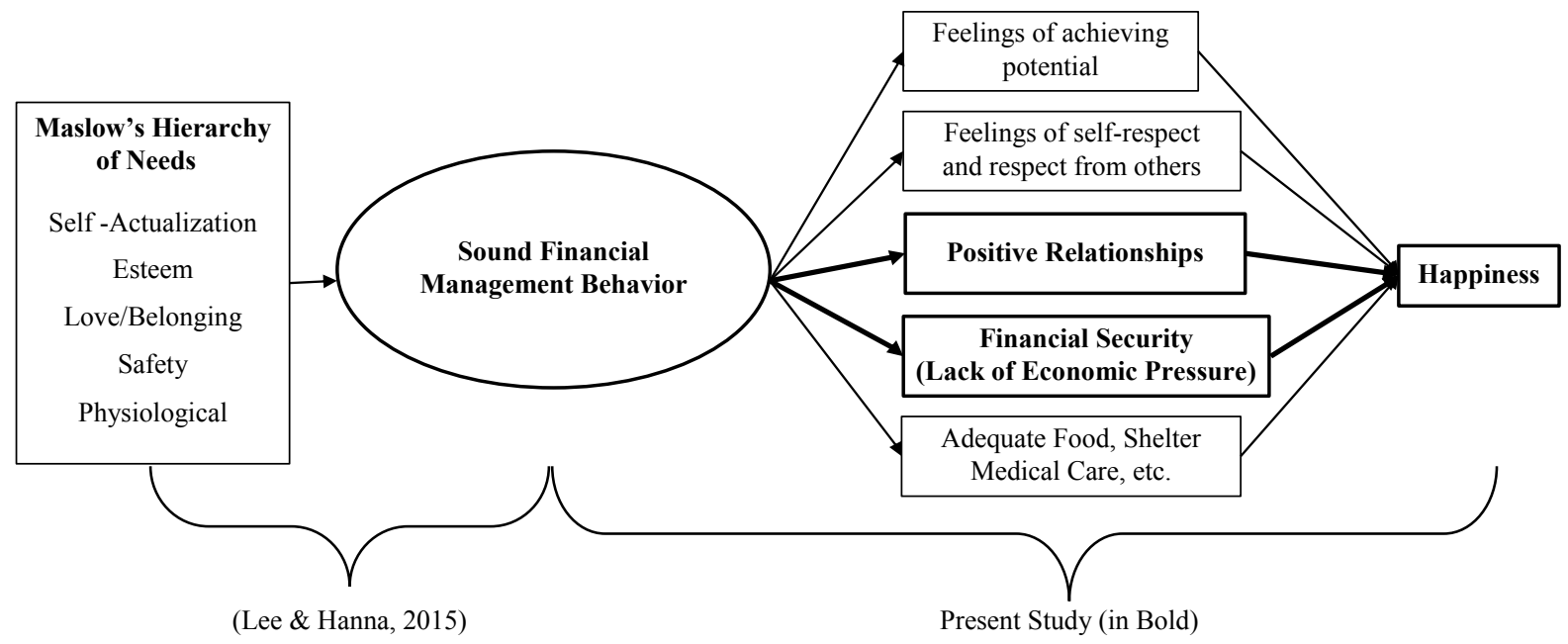

The purpose of our study is somewhat different. While prior studies (Lee \& Hanna, 2015; Xiao \& Noring, 1994) used needs to predict savings behavior; we examine whether sound financial management behaviors are associated with participants' reports of outcomes that represent needs. That is, we examine whether sound financial management behaviors actually helped participants satisfy needs - or at least whether sound financial management behaviors were associated with participants reports of outcomes that are related to needs. We then examine if these two reports are positively correlated.

We propose a conceptual model (Figure 1) that shows how sound financial management might operate within Maslow's hierarchy. First, expanding on Lee and Hanna's (2015) ideas, the various needs in the hierarchy may motivate sound financial management behavior. Sound financial management might then become a means or mechanism through which individuals actually meet those needs. The pathways between sound financial management and the need-based outcomes, and the pathways from the need-based outcomes to happiness, are the main research questions on which this study focuses. Our first research question is whether sound financial management relates to indicators of meeting basic needs, such as safety and security (i.e., as proxied by feelings of economic pressure) and love/belonging (i.e., as proxied by relationship satisfaction). Our second research question is whether the indicators of meeting basic needs mediate the association between sound financial management and happiness.

Unfortunately, data limitations prevent us from examining the entire conceptual model shown in Figure 1. We are neither able to test whether basic needs motivate sound financial management behaviors, nor do we have indicators of meeting all of the basic needs. But we are able to test whether the association between financial management and happiness is meditated by feelings of economic pressure and by feelings of relationship happiness. The bolded areas in Figure 1 represent what we can examine in the present study (see Figure 2 for our analytic model). We now examine previous literature that supports potential links between sound financial management behavior and meeting needs.

Safety/Security. Sound financial management behaviors might promote achieving feelings of safety and security. In Maslow's original monograph (1943), he specifically mentioned financial safety as part of overall safety. In their qualitative analysis of financial goals, Dilworth, Chenoweth, and Engelbrecht (2000) concluded that beyond meeting basic needs, money was a source of safety and security for both college students and their parents. Furthermore, Lee and Hanna (2015) suggested that feelings of safety and security were some of the top reasons for savings. According to their analysis, nearly $70 \%$ of the participants in the Survey of Consumer Finances gave a safety or security reason as their first response for saving. 
Figure 2. The analytic model of the mediated association between sound financial management and happiness.

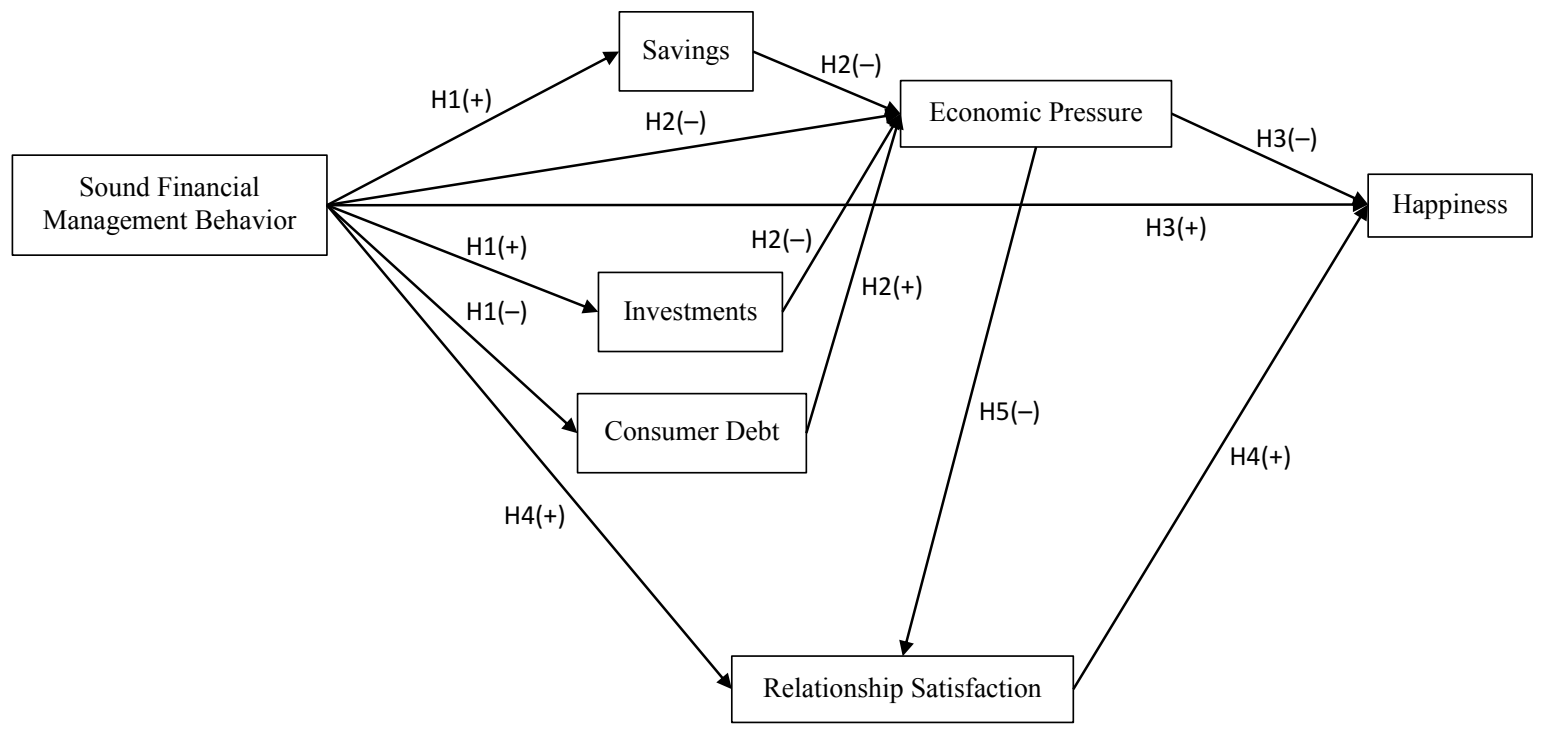

Individuals are often able to realize these safety needs by using sound financial management to increase their financial assets and decrease financial liabilities. Though this may seem like stating that grass is green, it is important to note that previous studies have found an association between financial management and greater wealth/lower debt. One national study showed that participants' reports of sound financial management were related to higher levels of liquid savings and investments and lower levels of consumer debt (Dew \& Xiao, 2013). In a study by Davis and Runyan (2016) financial behaviors such as positive money management skills and wealth-building activities were associated with stable financial situations. Another study showed that participation in a financial management program was associated with participants' improving their financial position (O’Neill, Prawitz, Sorhaindo, Kim, \& Garman, 2006).

H1 - Sound financial management behaviors are associated with higher levels of liquid savings and investments, and lower levels of consumer debt.

Economic pressure is defined as the day-to-day financial irritations and frustrations born out of an inability to make ends meet or provide for basic needs (Conger et al., 1992; Conger, Ge, Elder, Lorenz, \& Simons, 1994; Conger, Rueter, \& Elder, 1999; Dew \& Xiao, 2013). When households have more savings and less debt they report lower levels of economic pressure. In terms of Maslow's hierarchy, they report greater safety and security. Savings and investment behaviors, as well as securing insurance, help ensure that long-term financial needs can be met and individuals can be protected against disaster and hardships. One longitudinal study of married couples showed that Panel 1 asset levels were negatively associated with Panel 2 feelings of economic pressure and Panel 1 consumer debt levels were positively associated (Dew, 2007). Research conducted by Keefe and Fancey (1997) found that insufficient insurance and a lack of savings to cover the costs associated with aging, retirement, and possible long-term care was a significant source of financial worry. Litwin and Meir (2013) found similar results in their study of elderly populations. In short, many studies have found an association between financial assets, financial liabilities, and different measures of well-being (Aboagye \& Jung, 2018; Drentea, 2000; Muntaner, Eaton, Diala, Kessler, \& Sorlie, 1998; O’Neill, Sorhaindo, Xiao, \& Garman, 2005).

H2 - Sound financial management behaviors are associated with lower levels of economic pressure. Furthermore, savings, investments, and consumer debt will mediate the association between sound financial management behaviors and economic pressure. 
There may only be a partial mediation effect of savings, investment, and consumer debt on the association between sound financial management and economic pressure. Research has suggested that sound financial behavior is associated with feelings of security across different age groups. Shim et al. (2009) evaluated a variety of financial and other variables within a group of young college students as a means of describing both antecedents and consequences of financial well-being within this young population. Students who reported maintaining a financial plan including spending and credit management behaviors were more likely to be satisfied and feel secure. Additionally, individuals who use cash and credit management behaviors, may become less concerned that they will not be able to make ends meet in short-term situations and thus experience a reduction in their financial stress (Hodson, Dwyer, \& Neilson, 2014; Xiao, Sorhaindo, \& Garman, 2006).

As individuals experience less economic pressure, they are more likely to report higher levels of happiness. Economic pressure has been positively linked to depression and other types of negative effects (Dew, 2007; Gudmunson \& Danes, 2011). This connection can be seen quite clearly in those who experience a sudden onset of economic pressure due to unemployment. In their meta-analysis of unemployment research, McKee-Ryan, Song, Wanberg, and Kinicki (2005) identified consistent connections between well-being and economic pressure. Across 104 studies, unemployed individuals reported lower psychological well-being scores than their employed peers. Additionally, the presence of financial coping resources (the ability to continue to make ends meet while unemployed thereby lowering economic pressure) was strongly associated with improved well-being across these studies (McKee-Ryan et al., 2005).

H3 - Sound financial management behaviors are associated with higher levels of happiness. Furthermore, economic pressure mediates the associations between sound financial management behavior, savings, consumer debt, investments, and happiness.

Love and Belonging. A second pathway we test is whether reports of love and belonging mediate the association between sound financial management behavior and feelings of happiness. Sound financial management may help couples achieve their individually and jointly held goals. For example, sound financial management might help couples buy a home together or travel together during retirement if a couple maintains sound financial management, they may also be able to help one another reach an individually held goal, such as obtaining additional education. As couples achieve their individually and jointly held goals, their relationship satisfaction and individual happiness might then increase (Li \& Fung, 2011).

Although studies have demonstrated that associations between proxies of sound financial management and relationship quality exist (e.g., Dew, 2007; Gudmunson \& Danes, 2011), only a few studies have examined how actual sound financial management behaviors themselves are associated with relationship satisfaction. Using a national sample, Dew and Xiao (2013) found a positive association between sound financial management and relationship satisfaction. Another study found that perceptions of how well the finances were being managed were positively associated with reports of relationship satisfaction (Kerkmann, Lee, Lown, \& Allgood, 2000).

Many studies have found evidence for the second part a positive association between relationship satisfaction and happiness. Indeed, one study used meta-analytic techniques and found that marital happiness was linked to individual wellbeing across over 90 studies (Proulx, Helms, \& Buehler, 2007), whereas another found this same link across multiple countries (Stack \& Eshleman, 1998). Although less studied, it is likely that when cohabiting couples have better relationships, they also experience higher levels of individual well-being.

H4-Relationship satisfaction mediates the association between sound financial management and happiness.

Economic pressure has also been associated with relationship satisfaction in past studies (Conger et al., 1990; Dew $\&$ Xiao, 2013). The family stress model outlined in Conger et al. (1990) article describes a pathway from economic pressure to relationship distress resulting in decreased relationship satisfaction. This model has been validated in both domestic (United States) and international studies in the years since it was first published (Dew, 2007; Gudmunson \& Danes, 2011; Kwon, Rueter, Lee, Koh, \& Ok, 2003). While 
testing the association between economic pressure and relationship satisfaction is not a core purpose of this study, the association found between the two variables in past studies warrants the inclusion of this relationship in our proposed model.

H5-Economic pressure is negatively associated with relationship satisfaction.

\section{Income and Happiness}

In a study such as this, it is important that we acknowledge the link between income and happiness. In the early 1970s, Richard Easterlin identified a paradox involving the association between income and happiness. His cross-sectional data suggested a positive relationship, but longitudinal data both between and within nations found no relationship (Easterlin, 1973; Easterlin, McVey, Switek, Sawangfa, \& Zweig, 2010). This paradox has been a source of debate since it was first reported. Newer studies, however, have found associations between income and happiness that persist in longitudinal data (Stevenson \& Wolfers, 2008; Veenhoven \& Vergunst, 2014). Though a debate exists as to whether this association is linear (Kahneman, Krueger, Schkade, Schwarz, \& Stone, 2006; Stevenson \& Wolfers, 2013) or exhibits a threshold effect (Frey \& Stutzer, 2002), most contemporary studies do find that income and happiness are linked.

Income is arguably the simplest single-item measure of financial status. But income alone provides an incomplete picture of an individual's financial situation, which may explain the variability in past studies. Income is a variable that fluctuates over time and may be susceptible to changes in life situations (Dynarski \& Sheffrin, 1985; Nichols \& Zimmerman, 2008). Thus, there may be other financial variables that relate better to happiness.

One example is a study of depression. Zimmerman and Katon (2005) examined associations between income, other financial variables, and symptoms of depression. They found that while income was related to depressive symptoms, as soon as other economic variables were included in their model, the effect of income on depression fell to nonsignificant levels. Employment status and debt-to-income ratios emerged as more robust correlates of depression than income. Thus, Zimmerman and Katon's (2005) findings suggest that utility exists in looking beyond income at other financial issues when trying to explain happiness. We also seek to move beyond the income-happiness debate.

Our focus on sound financial management behaviors does not deny the importance of income, however, because income can shape financial management behaviors. Indeed, without an income, there is not much to manage. In their study of low-income families and their saving behaviors, Beverly and Sherraden (1999) found that these families were often lacking in surplus income and, thus, were unable to participate in savings behaviors. A more recent study echoed this same result. In their study of sound financial behaviors, Garasky, Nielsen, and Fletcher (2008) noted that the ability to participate in many of these sound financial behaviors was contingent on having enough income to first meet one's current financial obligations. Accordingly, we control for income levels on each of the endogenous variables in our model.

\section{The Individual Context}

Finally, the influence of financial behaviors on happiness cannot be assessed in a vacuum. Contextual factors also exist which must be considered. Education, for example, might be another resource that individuals draw from to enhance their security and/or happiness. Accordingly, in our analyses we control for age, number of children in the home, employment, education, and race/ethnicity so that our findings will stand independent of these contextual factors.

\section{Methods \\ Data and Sample}

We used data from the Familial Response to Financial Instability Study, a national, publically available, secondary data set. The survey was collected to assess U.S. individuals' financial management behaviors following the 2007 to 2009 Recession (see Dew \& Xiao, 2011). It includes responses to questions about financial management behaviors, questions regarding life and relationship satisfaction, and basic demographic questions.

This data was collected in August of 2009, shortly after the end of the 2007 to 2009 Recession. A survey research firm, Knowledge Networks, collected the data using their preexisting Knowledge Panel. The Knowledge Panel is a nationally representative (i.e., United States) sample of adults that was recruited using both random digit dialing 
and random address-based sampling and stratified random sampling techniques.

Knowledge Networks asked 1,517 individuals in Knowledge Panel to participate in the Familial Response to Financial Instability Study. 1,014 participants agreed to do so; this represented a $67 \%$ participation rate. For this analysis, we used data from all who participated in the Familial Response to Financial Instability Study $(N=1,014)$.

\section{Measures}

Dependent Variable. The dependent variable was a measure of participants' overall happiness. Specifically, participants responded to the question, "Taking things all together, how would you say things are these days?" The response set ranged from 1 (Very Unhappy) to 7 (Very Happy).

Exogenous Variable. We used the revised version of the Financial Management Behavior Scale (FMBS) to measure participants' sound financial management. The FMBS measured the frequency of individual's financial management behaviors over the previous 6 months in four areas - cash management (e.g., "kept a written or electronic record of your monthly expenses"), credit management (e.g., "paid off credit card balance in full each month"), savings and investment (e.g., "saved for a long-term goal such as a car, education, home, etc."), and insurance (e.g., "maintained or purchased an adequate health insurance policy"). The scale is made up of 15 items (see Dew \& Xiao, 2011 for a full list of the revised measures). The response set ranges from 1 (Never) to 5 (Always). To get the FMBS score, we took the mean of the 15 items from all 4 domains. Previous studies have shown that the FMBS is a reliable and valid measure of individuals' sound financial management (Dew \& Xiao, 2011). In this particular study, Chronbach's alpha for the FMBS was .84 .

Mediator Variables. The Familial Response to Financial Instability survey also asked participants to report their levels of savings, investments, and consumer debt. The savings question focused on liquid forms of assets and asked participants "What is the approximate total value of your savings, including savings accounts, government savings bonds, money market shares, and certificates of deposit?" The consumer debt question asked participants "What is the approximate total value of your current credit card debt, installment loans, and past-due bills?" Finally, the investment variable asked participants "What is the approximate total value of your investments, including stocks, corporate bonds, mutual funds, individual retirement accounts, or other investments?" For all three of these items, participants could respond from 1 (None) to 9 (\$100,000 or More).

We assessed economic pressure through a single item. This item asked participants "How often do you worry that your total family income will not be enough to meet your family's expenses and bills?" Participants could respond from 1 (Never) to 5 (Almost all the time).

We assessed relationship satisfaction through a single item. This item asked cohabiting or married participants, "Taking things all together, how would you describe your marriage/relationship these days?" The response set ranged from 1 (Very Unhappy) to 7 (Very Happy). Participants who were not cohabiting or married did not receive this question.

Control Variables. We also included some variables as control covariates. Total Household Income was measured on a 19-point scale that ranged from 1 (Less than $\$ 5,000$ ) to 19 (\$175,000 or more). Age was measured in years. Education was measured using three dummy-coded variables. Participants who had only completed high school received the code of "1" on the High School variable. Participants who had attended some college but had not completed a 4 -year degree received the code of "1" on the Some College variable. Finally, participants who had completed a 4year college degree or even more education received the code of "1" for the College Degree variable. The omitted category was for those who had not finished high school. We also included employment status in the model. We measured employment status using two dummy variablesfull-time status and part-time status. The comparison group is not employed. Unfortunately, we were not able to disentangle those who are unemployed and those who are not in the labor force in this comparison group. We also had race/ethnicity in the model. We used two dummy-coded variables-Black (Non-Hispanic), and other race/ethnicity. The comparison category was White, Non-Hispanic. We also controlled for marital and cohabitation status in the full analysis (the omitted category was single, not cohabiting) and for cohabitation status in the second analysis (the omitted category was married). Finally, we also controlled for the number of children in the home. 


\section{Analysis}

We used two path analyses with bootstrapping to test the hypotheses (see Figure 2). We used path analyses because Figure 2 specified that many regressions would be running simultaneously; path analysis allows simultaneous regressions. Using bootstrapping allowed us to generate the size of the indirect (or mediating) effects and test them for statistical significance (Hayes, 2009). Bootstrapping takes multiple random samples, with replacement, from the data; we specified 200 random samples. It then uses these random samples to estimate the size of the direct and indirect effects in the models. This is one of the premier techniques for estimating indirect effects (Hayes, 2009). We used AMOS 24.0 to conduct the analysis.

The first path analysis was similar to Figure 2, but did not contain the relationship satisfaction question. We conducted the first analysis without the relationship satisfaction question because about half of the participants, those who were not in a cohabiting or marital relationship, did not receive the relationship satisfaction question. Conducting the analysis with the relationship question would have dropped half of the participants, and we wanted to evaluate Hypotheses 1 to 3 with the full sample. The second path model conducted the full analysis specified in Figure 2 with just the subset of participants who were in a cohabiting or marital relationship. We formally tested whether the findings in the first path model differed when we had the whole sample versus just the individuals who were in relationships. There were no differences in the regression intercepts and coefficients between these two models.

Only $5 \%$ of participants had one or more variables missing. We examined the findings using listwise deletion and mean imputation (Paul, Mason, McCaffrey, \& Fox, 2008). Given the large sample size and the small number of participants with missing data, it is perhaps unsurprising that the different missing data treatments failed to generate meaningful differences in the path models. We report the results from the mean-imputed data because they were the most conservative. That is, the coefficients in the mean-imputed models were smaller than those in the listwise deleted model.

\section{Results}

\section{Descriptive Statistics}

Table 1 shows the descriptive statistics of the sample. Overall, participants reported being slightly happier than unhappy. That is, the mean for overall life happiness (4.41) was slightly above the midpoint of the item. The mean for the FMBS (3.48 out of 5) suggested that participants reported engaging in sound financial management at a level somewhere between "sometimes" (i.e., a score of 3 ), and "often" (i.e., a score of 4). The mean for savings (4.42) and investments (4.44) corresponded to a level somewhere between the " $\$ 3,000$ to under $\$ 5,000$ " range and the " $\$ 5,000$ to under $\$ 10,000$ " range. The mean for consumer debt (3.49) corresponded to a level between the ranges of " $\$ 1,500$ to under $\$ 3,000$ " and " $\$ 3,000$ to under $\$ 5,000$." Participants" reported their feelings of economic pressure nearly at the midpoint of the item. That is, participants reported worrying that their income will not be enough to meet their expenses "once in a while" on average. The mean of income, near 11 , corresponds to an income level between $\$ 40,000$ and $\$ 50,000$. The descriptive statistics for the control covariates can also be found in Table 1 .

\section{Path Models}

Model Without Relationship Satisfaction. Table 2 and Figure 3 show the results for the path model without relationship satisfaction. Table 2 gives all of the results in unstandardized format, whereas Figure 3 shows the overall model with standardized coefficients. Figure 3 also omits the control covariates for the sake of clarity, though they were in the model.

First, the model fit statistics were good. The $\chi^{2}$ statistic was not significant $\left(\chi^{2}=16.34,9\right.$. Further, Other fit statistics were strong; the CFI was .99 while the RMSEA was .03 .

Figure 3 shows the path model. The model performed as hypothesized. Specifically, participants' reports of their sound financial management behavior were positively associated with their reports of savings $(\beta=.40, p<.001)$ and investment $(\beta=.34, p<.001)$ amounts. Reports of sound financial management were negatively associated with reports of consumer debt amounts $(\beta=-.23, p<$ $.001)$. In the next step of the model, savings were negatively related $(\beta=-.14, p<.01)$ and consumer debt was positively related $(\beta=.16, p<.001)$ to feelings of economic pressure. Investment amounts were not related to feelings of economic pressure. Interestingly, however, even with savings and consumer debt in the model, participant reports of sound financial management behavior still had a direct and negative association with feelings of 
Figure 3. The mediated association between sound financial management and happiness without relationship satisfaction $(N=1,014)$.

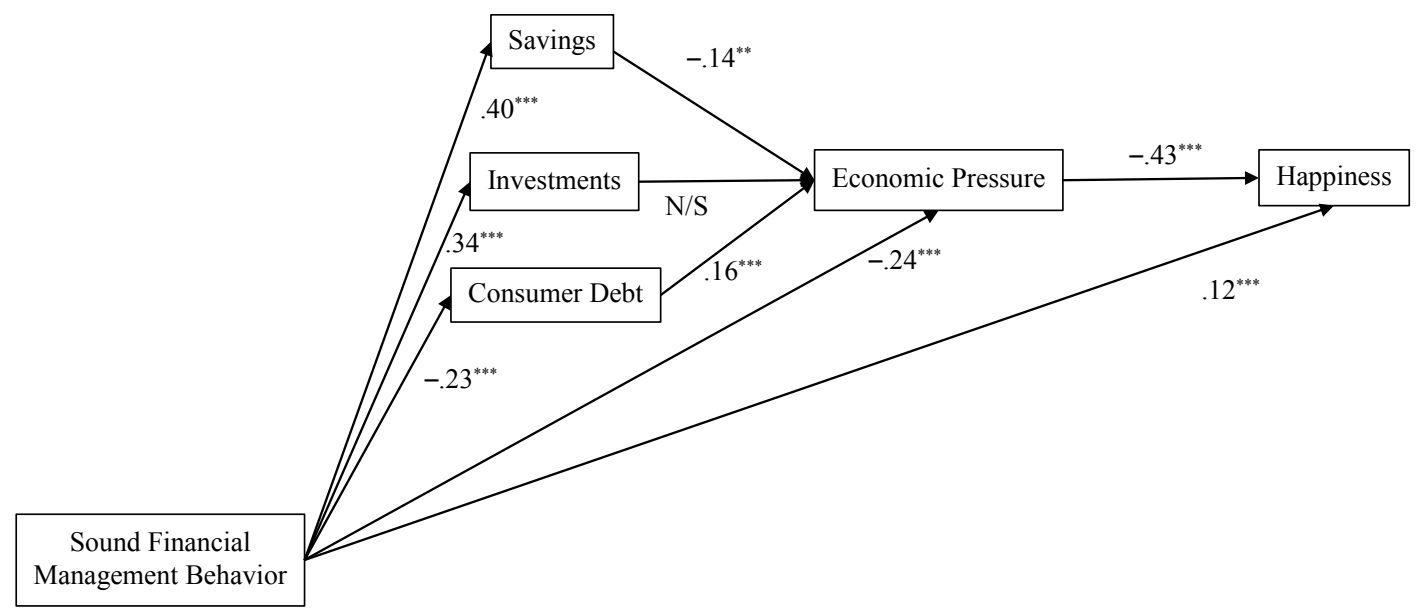

Note. Standardized coefficient shown. Control covariates were omitted for clarity. They included age, education, employment status, number of children in the home, marital/cohabiting status, and race/ethnicity.

$\chi^{2}=16.34 ; d f=9 ; \mathrm{CFI}=.99 ;$ RMSEA $=.03$.

${ }^{*} p<.05 .{ }^{* *} p<.01 . * * * p<.001$.

economic pressure $(\beta=-.24, p<.001)$. As hypothesized, economic pressure was negatively related to happiness $(ß=-.43, p<.001)$. Again, however, even with economic pressure in the model, participants' reports of sound financial management behavior were positively associated with happiness $(ß=.12, p<.001)$.

We tested some of the indirect associations. The standardized indirect association between income and happiness $(ß=.15)$ was statistically significant at the $p<.05$ level. Furthermore, the indirect association between sound financial management and life happiness $(B=$ .14) was also statistically significant (at the $p<.01$ level), even though a direct effect still persisted in this model $(\beta=.12, p<.001)$. The indirect effects of savings $(B=.06, p<.05)$ and debt $(B=-.07$, $p<.01)$ on happiness were also statistically significant.

Table 2 gives more information about the models. In addition to the associations between the different control covariates and the main variables in the model, it also gives the variance that the model accounts for in the mediator variables and the dependent variable. The model explained $24 \%$ of the variance in reports of sound financial management. It explained $48 \%, 44 \%$, and $14 \%$ of the variance in savings, investments, and consumer debt respectively. The model explained $26 \%$ of the variance in participants' feelings of economic pressure. Finally, it explained $23 \%$ of the variance in life happiness.

Model With Relationship Satisfaction. Table 3 and Figure 4 show the results for the path model that included relationship satisfaction. This model only used the data from 550 individuals in it because that was the number of participants who were married or cohabiting. If participants were not married or cohabiting, they did not receive the relationship satisfaction question. Table 3 uses unstandardized coefficients; Figure 4 uses standardized coefficients. Like Figure 3 , Figure 4 omits the control covariates.

First, the model fit statistics were good. The $\chi^{2}$ statistic for this model was significant $\left(\chi^{2}=16.40,7, p<.001\right)$. Statistically significant $\chi^{2}$ statistics sometimes occur with larger sample sizes (Yadama \& Pandey, 1995). Other fit statistics were strong; the CFI was .99 while the RMSEA was .05 .

Figure 4 shows the path model. Not surprisingly, many of the findings were the same as the previous model. Participants' reports of sound financial management were positively associated with their reports of savings $(\beta=.45$, 
Figure 4. The mediated association between sound financial management and happiness with relationship satisfaction $(N=550)$.

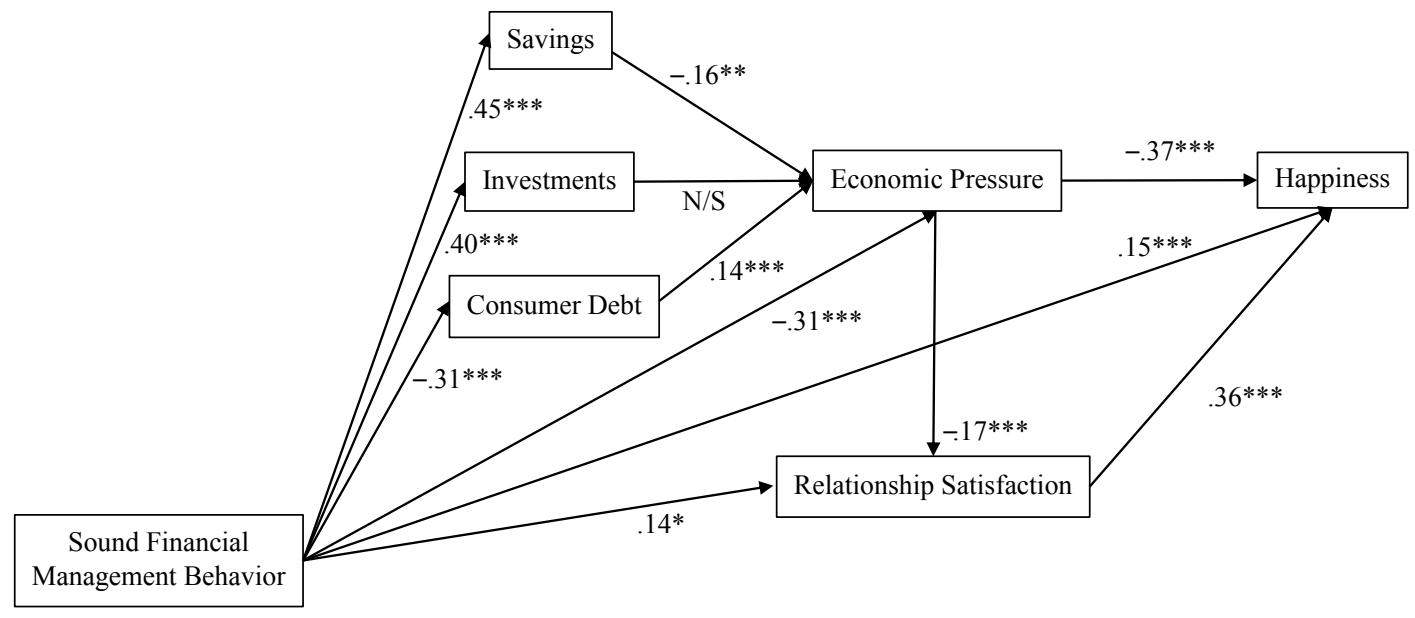

Note. Standardized coefficient shown. Control covariates were omitted for clarity. They included age, education, employment status, number of children in the home, cohabiting status, and race/ethnicity.

$\chi^{2}=16.40^{*} ; d f=7 ; \mathrm{CFI}=.99 ; \mathrm{RMSEA}=.05$.

${ }^{*} p<.05 .{ }^{* *} p<.01 .{ }^{* * *} p<.001$.

$p<.001)$ and investments $(\beta=.40, p<.001)$, and negatively associated with reports of consumer debt amounts $(\beta=-.31, p<.001)$. Furthermore, savings was negatively related $(B=-.16, p<.01)$ and consumer debt was positively related $(\beta=.14, p<.001)$ to feelings of economic pressure. Investment amounts were not related to feelings of economic pressure. Reports of sound financial management behavior had a direct and negative association with feelings of economic pressure $(\beta=-.31, p<.001)$, and economic pressure was negatively related to happiness $(\beta=-.37, p<.001)$ and relationship satisfaction $(\beta=-.17$, $p<.001)$.

This analysis also found an indirect pathway between sound financial management behaviors and life happiness through relationship satisfaction. Sound financial management behaviors were positively associated with relationship satisfaction $(\beta=.14, p<.001)$. Relationship satisfaction was then associated with happiness $(\beta=.36, p<$ .001). Finally, participants' reports of sound financial management behavior were positively associated with happiness $(\beta=.15, p<.001)$ even with the other mediators in the model. AMOS did not allow us to conduct a separate test of the indirect effect of sound financial management on happiness through relationship satisfaction, only a test of the indirect of financial management on happiness through all pathways. This test $(\beta=.20, p<.01)$ was statistically significant and was larger than the indirect relationship in the first path model.

\section{Discussion}

\section{Findings and Research Implications}

Using the theoretical lens of Maslow's hierarchy of needs, this study explored the association between sound financial management behaviors and happiness. Lee and Hanna (2015) demonstrated a connection between the Maslow's needs and sound financial management behaviors. This study sought to take the next theoretical step to determine if those behaviors are in fact associated with reports of having those needs fulfilled and if they are likewise associated with happiness (see Figure 1). As our data did not allow for a detailed examination of all of Maslow's identified needs, we limited our study to a focus on the needs of safety and security as indicated by financial well-being or a lack of economic pressure and love and belonging as indicated by relationship satisfaction. We proposed four hypotheses in this conceptual framework.

Our first hypothesis was that sound financial management behaviors would be associated with liquid savings, 
TABLE 1. Descriptive Statistics (Full Sample)

\begin{tabular}{|c|c|c|c|}
\hline & $\begin{array}{l}\text { Mean or } \\
\text { Percentage }\end{array}$ & $S D$ & $\begin{array}{l}\text { Minimum- } \\
\text { Maximum }\end{array}$ \\
\hline $\begin{array}{l}\text { Overall life } \\
\text { happiness }\end{array}$ & 4.41 & 1.49 & $1-7$ \\
\hline $\begin{array}{l}\text { Sound financial } \\
\text { management } \\
\text { (FMBS) }\end{array}$ & 3.46 & .88 & $1-5$ \\
\hline Savings & 4.42 & 2.85 & $1-9$ \\
\hline Consumer debt & 3.49 & 2.36 & $1-9$ \\
\hline Investments & 4.44 & 3.23 & $1-9$ \\
\hline $\begin{array}{l}\text { Economic } \\
\text { pressure }\end{array}$ & 3.06 & 1.24 & $1-5$ \\
\hline Income & 10.96 & .13 & $1-19$ \\
\hline Age & 49.39 & .52 & $18-90$ \\
\hline $\begin{array}{l}\text { Number of } \\
\text { children in home }\end{array}$ & .52 & .03 & $0-8$ \\
\hline $\begin{array}{l}\text { Full-time } \\
\text { employment }\end{array}$ & $42 \%$ & & \\
\hline $\begin{array}{l}\text { Part-time } \\
\text { employment }\end{array}$ & $12 \%$ & & \\
\hline $\begin{array}{l}\text { High school } \\
\text { degree }\end{array}$ & $29 \%$ & & \\
\hline Some college & $31 \%$ & & \\
\hline College degree & $28 \%$ & & \\
\hline Black & $7.6 \%$ & & \\
\hline $\begin{array}{l}\text { Other } \\
\text { race/ethnicity }\end{array}$ & $15 \%$ & & \\
\hline Married & $48.2 \%$ & & \\
\hline Cohabiting & $8.6 \%$ & & \\
\hline
\end{tabular}

Note. FMBS $=$ Financial Management Behavior Scale.

investments, and consumer debt. Consistent with that hypothesis, we found positive relationships between sound financial management behaviors and savings and investment amounts as well as a negative association between sound financial management behaviors and levels of reported consumer debt. While this may seem intuitive, we wanted to first demonstrate a connection between sound financial management behaviors and the participants' current financial status so that we could partial out that part of the model.

Our second hypothesis was that levels of savings, investment, and consumer debt would mediate the association between sound financial management behaviors and economic pressure. The results only partially supported this hypothesis. First, as described earlier, investments were not significantly associated with economic pressure and consequently did not mediate the relationship between sound financial management behaviors and economic pressure. Second, the other two measures of financial status, savings, and consumer debt, only partially mediated the relationship between sound financial management behaviors and economic pressure. With savings and consumer debt in the model, there was still a direct and negative association between sound financial management behaviors and economic pressure. This finding suggests, but cannot prove, that participating in sound financial management behaviors may reduce economic pressure above and beyond the impact that it may have on improving one's financial situation. To put this in terms of Maslow's hierarchy (see Figure 1), it would appear that the use of sound financial management behaviors is associated with financial peace of mind beyond the association these behaviors have with one's financial status.

Our third hypothesis stated that economic pressure would mediate the association between sound financial management behavior, savings, debt, investments, and happiness. Again, we found only partial mediation. With economic pressure in the model, there was no significant relationship between savings, investment, or debt with happiness, indicating that their effect on happiness was fully mediated by economic pressure. But the same was not true for sound financial management behaviors. There we found evidence of only partial mediation as there was still a significant association between sound financial management behaviors and happiness with economic pressure in the model. This is not to be taken as a sign that the model is not supported, but rather that participation in sound financial management behaviors is associated with happiness through more than just reductions in economic stress. As discussed in Zhao, Lynch, and Chen's (2010) article, the strength of a mediated model lies not in its lack of a direct effect (i.e., full mediation), but in the strength of the indirect effect, and partial mediation only highlights the opportunity for further evaluation of the relationships and exploration of other possible mediators. In this case, the strength of the indirect effect is clear evidence that much of the relationship between sound financial management behaviors and happiness is mediated through economic pressure. Perhaps, the remaining direct 


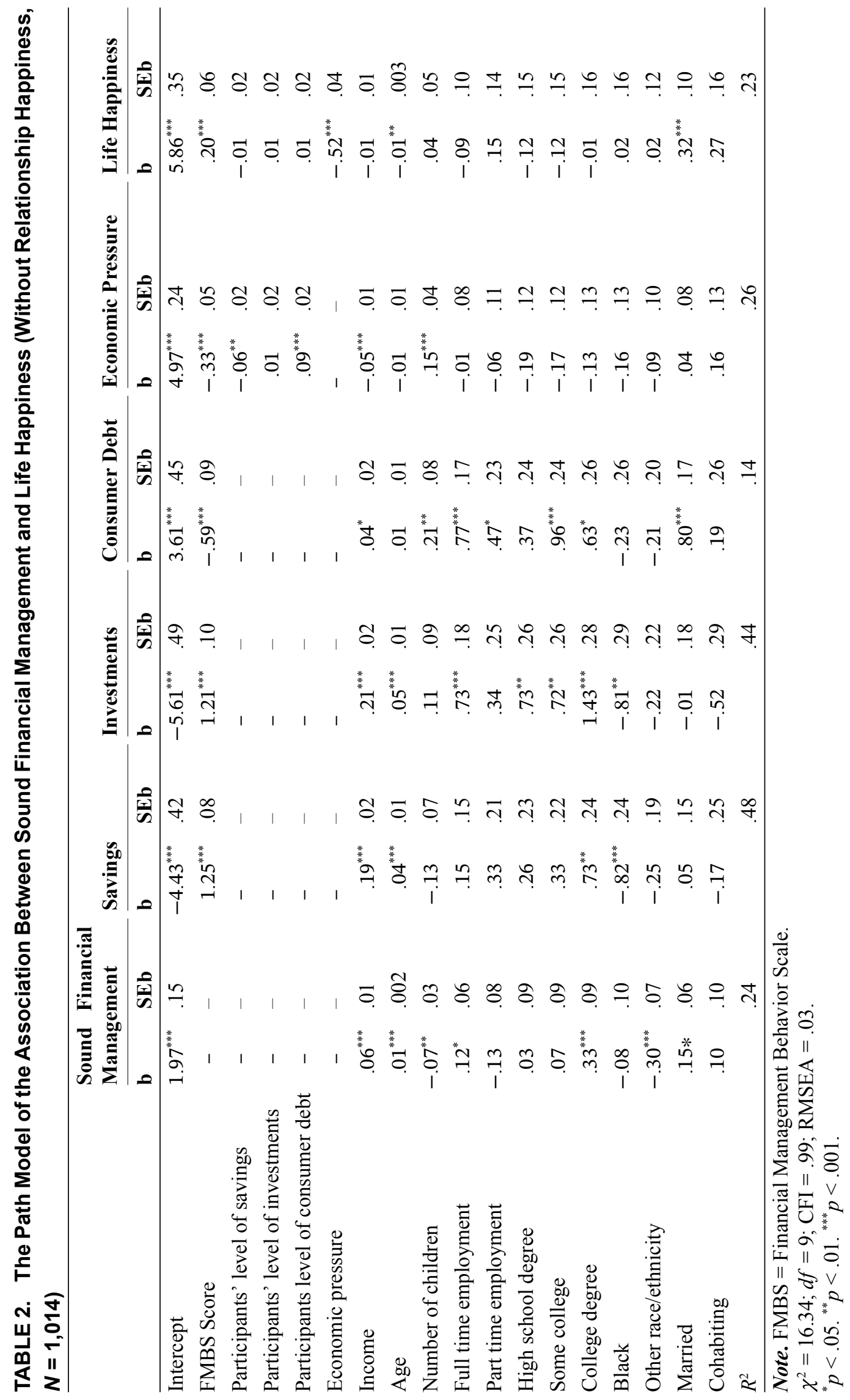




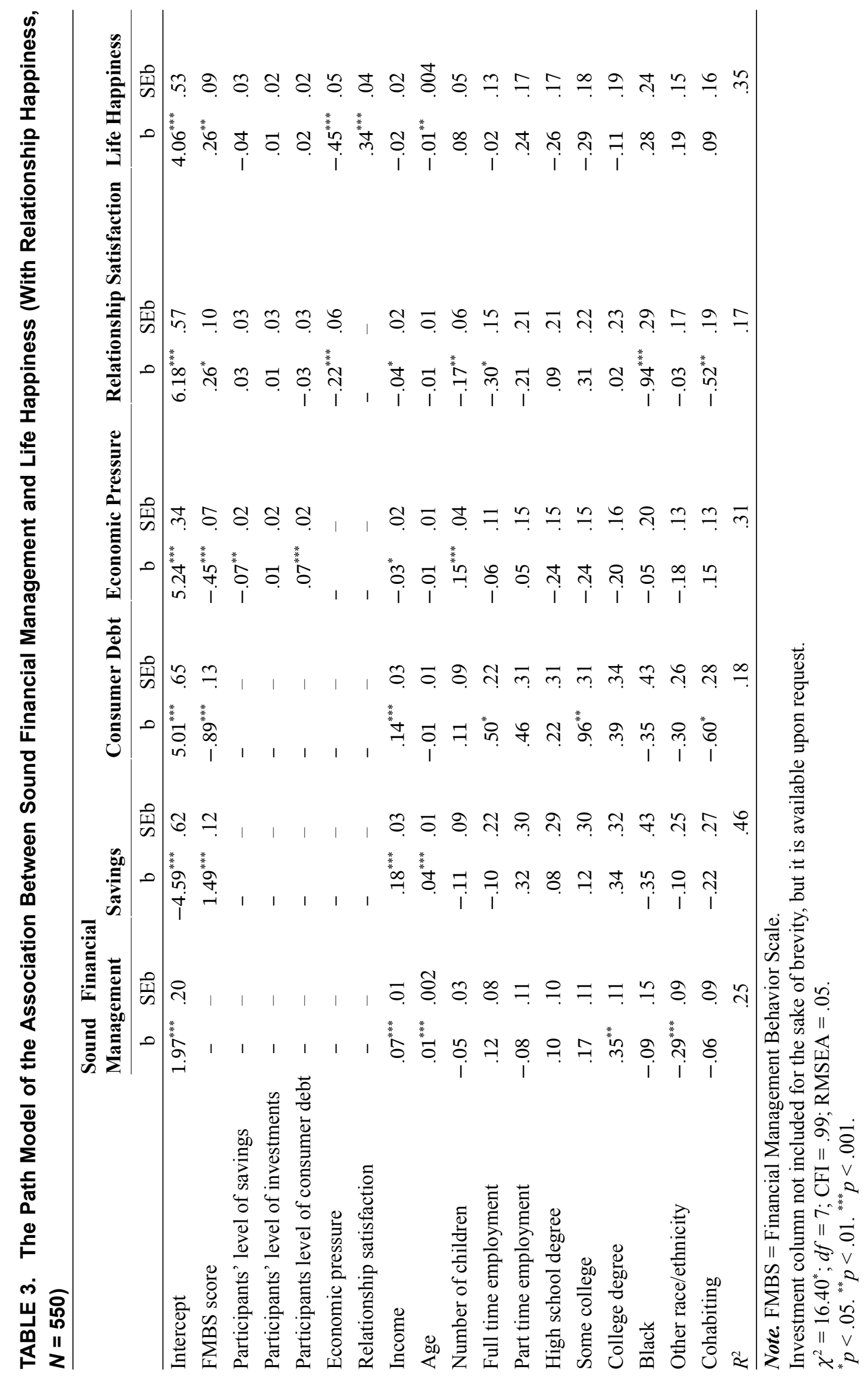


effect between sound financial management behaviors and happiness is due to a sense of fulfillment that comes from behaving in a manner that one knows is financially responsible, or some other mediator that we were not able to include in our model. Additional research could help to shed light on other possible mediators that may play a role in this relationship.

Our fourth hypothesis was that relationship satisfaction would mediate the association between sound financial management and happiness. As would be expected from prior literature (Dew \& Xiao, 2013; Proulx et al., 2007; Stack \& Eshleman, 1998), sound financial management behaviors were positively associated with relationship satisfaction which was then, in turn, positively associated with happiness. This is evidence of the pathway through which the hypothesized mediation may occur. However, the relationship between sound financial management behaviors and happiness was only partially mediated through relationship satisfaction as a direct association between them was still present even with relationship satisfaction in the model (see Figure 4). Again, this is likely due to additional mediators that we were not able to test with our data. Consistent with the prior literature, the associations between sound financial management behaviors and relationship satisfaction exist, which, in turn, is associated with happiness as is demonstrated in our model. However, just as was the case with our third hypothesis discussed earlier, as we are not measuring all of the possible influencers on happiness, we cannot fully capture every potential mediator.

Our fifth hypothesis was that economic pressure would be negatively associated with relationship satisfaction. Again, our findings here were consistent with past studies (Conger et al., 1990; Dew, 2007; Dew \& Xiao, 2013; Gudmunson, Beutler, Israelsen, McCoy, \& Hill, 2007; Kinnunen \& Pulkkinen, 1998; Kwon et al., 2003) in that higher reports of economic pressure were associated with lower reports of relationship satisfaction among coupled participants. While it appears that economic pressure may mediate the effect of sound financial management behaviors on relationship satisfaction, it is only a partial mediation as a direct relationship still exists. Just as with the two prior hypotheses, this is further evidence of the interconnected relationships between the variables in this model. Future studies designed to tease apart these complex relationships could help to further shed light on the interplay between these variables.
These findings support the idea that sound financial management behaviors have associations with variables beyond their associations with one's financial status. In addition to the direct effects they had with economic pressure and relationship satisfaction, sound financial management behaviors also had a direct effect on happiness beyond that which can be attributed to economic pressure or relationship satisfaction. Coupled with the findings related to our second hypothesis, this finding suggests that the benefits of using sound financial management behaviors include, but also extend beyond their impact on current financial situations, economic pressure, or relationship satisfaction.

It is possible that the use of sound financial behaviors helps to fulfill the rest of Maslow's needs. While we could not test this idea in our study, the persistence of the direct effect of sound financial management behaviors on happiness beyond economic pressure and relationship satisfaction may be due these behaviors helping individuals to meet survival needs, esteem needs, or to feelings of achievement (i.e., self-actualization). Additional research in this area could help shed light on the further mechanisms through which sound financial management behaviors may influence happiness.

This study has important implications for further research. By emphasizing the positive associations of sound financial management behaviors with outcomes beyond just bottomline financial outcomes like debt, savings, and investment amounts this study highlights the process through which reduction in financial stress and gains in happiness might be attributed to the use of sound financial management behaviors. This study also serves to help answer Israelsen and Hatch's (2005) call from for more proactive research related to family financial management. The outlined theoretical framework builds on Maslow's hierarchy of needs and describes pathways through which happiness may be studied in light of those needs. As this study was limited to just two of the five needs in Maslow's hierarchy, further research could help to address the other three needs and identify the ways in which sound financial management behaviors may be associated with meeting those needs. Furthermore, future research might study the domains of sound financial management in more detail to see if certain behaviors (e.g., insurance) relate to certain needs (e.g., security) more than other behaviors. 


\section{Limitations}

This study is not without its limitations. As in all cases where associations are observed in only a single time period, cause, and effect relationships cannot be determined, only theorized. While theory helped to shape our pathway analysis, we acknowledge that the direction of the associations we describe can only be theorized within this data. While it seems intuitive that participating in sound financial management behaviors would lower economic stress, it could also be argued that those who feel less economic stress are more inclined to make more sound financial decisions because they are not under intense pressure and won't resort to strategies like credit spending to reduce that stress in the short term. This directionality limitation may extend to the other findings in the study as well. When combined with the limitation of selection effects, it could be argued that people who are inherently more satisfied with life are less likely to report economic stress which could then lead to the use of more sound financial management behaviors as was just explained. While we feel that this scenario is less likely than the pathway we spelled out in our hypotheses, the use of only a single time point limits our ability to rule out the possibility that the direction may be reversed and state that causality has been clearly demonstrated.

We would also be remiss if we did not address the possible period effect within this data. Given that the data were collected at the end of the 2007 to 2009 Recession, the salience of financial issues and financial management might be stronger for our participants than if the data had been collected later-say in 2014. The Recession may account for some of the strength and persistence in the relationship between sound financial management behaviors and happiness. The mediators, for example, might have more fully mediated the association between sound financial management and happiness in a different time period. As we have noted, additional research is warranted.

In addition to these limitations, there are also limitations in the measures themselves. As noted earlier, most of the variables collected consisted of single-item measures. This may limit the reliability of the measures in fully capturing the desired constructs to the same degree as a multi-item measure of the same construct. Further research using more in-depth measures gathered across multiple time points could help strengthen the findings in this study and better elucidate the nature of the mechanisms at work between sound financial management behaviors and happiness.

\section{Implications for Practitioners}

Practitioners may be able to use these findings. The fact that sound financial management behaviors were still related to lower levels of economic pressure and higher levels of relationship satisfaction and happiness even after controlling for participants' financial situation demonstrates the life gains that might be made using sound financial management behaviors. Service providers might use these findings to help motivate clients. Not only might sound financial management improve one's financial position, but these behaviors might also have spillover benefits. A practitioner may highlight these potential spillover benefits as a means to motivate their clients to continue to make sound financial management decisions even when their financial goals may seem too far distant. This might be similar to how a doctor or fitness coach might increase a patient's/client's motivation to adhere to a diet/exercise routine by suggesting that such a routine will increase their emotional well-being and energy levels even before they see significant changes on their bathroom scale.

Financial planning often focuses on behavior changes in the present in order to get on the right financial path with the promise that continued progress on that path will lead to benefits in the future. Perhaps practitioners may use the results of this study to highlight some of the benefits that may also be enjoyed by their clients along the way to their financial goals. One method for doing this would be to propose a trial period with clients wherein they participate in sound financial management behaviors for a short period (perhaps only a few months depending on the willingness of the client to participate). The practitioners could then follow-up regularly with their clients over that period to assess both the client's adherence to the behavioral goals and their overall feelings of financial pressure, relationship satisfaction, and overall happiness. Any reported changes could then be used as motivation toward continuing behaviors and extending goals.

Furthermore, the findings of this study validate a maxim that one hears from practitioners. Our analyses found that what participants did with their income mattered more for their happiness than their actual income itself. Indeed, the 
standardized total effect of sound financial management behaviors on happiness (.36) had a magnitude that was seven times that of income (.36 vs. .05, respectively) and the standardized total effect for income was not even statistically significant. This may also serve a motivating factor for clients as practitioners work to shift their clients' focus from their income to their financial behaviors.

\section{References}

Aboagye, J., \& Jung, J. Y. (2018). Debt holding, financial behavior, and financial satisfaction. Journal of Financial Counseling and Planning, 29(2), 208-218. doi:10.1891/1052-3073.29.2.208

Baek, E., \& DeVaney, S. A. (2010). How do families manage their economic hardship? Family Relations, 59(4), 358368. doi:10.1111/j.1741-3729.2010.00608.x

Beverly, S. G., \& Sherraden, M. (1999). Institutional determinants of saving: Implications for low-income households and public policy. The Journal of SocioEconomics, 28(4), 457-473. doi:10.1016/S1053-5357 (99)00046-3

Conger, R. D., Conger, K. J., Elder, G. H., Lorenz, F. O., Simons, R. L., \& Whitbeck, L. B. (1992). A family process model of economic hardship and adjustment of early adolescent boys. Child Development, 63(3), 526541. doi:10.2307/1131344

Conger, R. D., Elder, G. H., Lorenz, F. O., Conger, K. J., Simons, R. L., Whitbeck, L. B., . . Melby, J. N. (1990). Linking economic hardship to marital quality and instability. Journal of Marriage and Family, 52(3), 643656. doi:10.2307/352931. Retrieved from http://www. jstor.org/stable/352931

Conger, R. D., Ge, X., Elder, G. H., Lorenz, F. O., \& Simons, R. L. (1994). Economic stress, coercive family process, and developmental problems of adolescents. Child Development, 65(2), 541-561. doi:10.2307/1131401. Retrieved from https://www.jstor.org/stable/1131401

Conger, R. D., Rueter, M. A., \& Elder, G. H. (1999). Couple resilience to economic pressure. Journal of Personality and Social Psychology, 76(1), 54-71. doi:10.1037/0022-3514.76.1.54

Davis, E. P., \& Weber, J. A. (1990). Patterns and obstacles to financial management. Financial Counseling and Planning, 1, 41-52. doi:10.1049/el.2015.0462

Davis, K., \& Runyan, R. C. (2016). Personality traits and financial satisfaction: Investigation of a hierarchical approach. Journal of Financial Counseling \& Planning, 27(1), 47-60. doi:10.1891/1052-3073.27.1.47

Dew, J. P. (2007). Two sides of the same coin? The differing roles of assets and consumer debt in marriage. Journal of Family and Economic Issues, 28(1), 89-104. doi:10.1007/s10834-006-9051-6

Dew, J. P., \& Xiao, J. J. (2011). The financial management behavior scale: Development and validation. Journal of Financial Counseling and Planning, 22(1), 43-59.

Dew, J. P., \& Xiao, J. J. (2013). Financial declines, financial behaviors, and relationship satisfaction during the recession. Journal of Financial Therapy, 4(1), 1-20. doi:10.4148/jft.v4i1.1723

Diener, E., Oishi, S., \& Lucas, R. E. (2003). Personality, culture, and subjective well-being: Emotional and cognitive evaluations of life. Annual Review of Psychology, 54(1), 403-425. doi:10.1146/ annurev.psych.54.101601.145056

Dilworth, J. L., Chenoweth, L. C., \& Engelbrecht, J. (2000). A qualitative study of the money goals of college students and their parents. Financial Counseling and Planning, 11(2), 33-42.

Drentea, P. (2000). Age, debt and anxiety. Journal of Health and Social Behavior, 41(4), 437-450. doi:10.2307/2676296

Dynarski, M., \& Sheffrin, S. M. (1985). Housing purchases and transitory income: A study with panel data. The Review of Economics and Statistics, 67(2), 195-204. Retrieved from http://www.jstor.org/stable/1924718

Easterlin, R. A. (1973). Does money buy happiness? The Public Interest, 30, 3-10.

Easterlin, R. A., McVey, L. A., Switek, M., Sawangfa, O., \& Zweig, J. S. (2010). The happiness-income paradox revisited. Proceedings of the National Academy of Sciences, 107(52), 22463-22468. doi:10.1073/ pnas. 1015962107

Frey, B. S., \& Stutzer, A. (2002). What can economists learn from happiness research? Journal of Economic Literature, 40(2), 402-435. doi:10.1257/jel.40.2.402

Garasky, S., Nielsen, R. B., \& Fletcher, C. N. (2008). Consumer finances of low-income families. In J. J. Xiao (Ed.), Handbook of consumer finance research (pp. 223-237). New York, NY: Springer. doi:10.1007/ 978-0-387-75734-6_13

Gudmunson, C. G., Beutler, I. F., Israelsen, C. L., McCoy, J. K., \& Hill, E. J. (2007). Linking financial strain to marital instability: Examining the roles of emotional 
distress and marital interaction. Journal of Family and Economic Issues, 28(3), 357-376. doi:10.1007/s10834007-9074-7

Gudmunson, C. G., \& Danes, S. M. (2011). Family financial socialization: Theory and critical review. Journal of Family and Economic Issues, 32(4), 644-667. doi:10.1007/s10834-011-9275-y

Hayes, A. F. (2009). Beyond Baron and Kenny: Statistical mediation analysis in the new millennium. Communication Monographs, 76(4), 408-420. doi:10.1080/ 03637750903310360

Hodson, R., Dwyer, R. E., \& Neilson, L. A. (2014). Credit card blues: The middle class and the hidden costs of easy credit. The Sociological Quarterly, 55(2), 315340. doi:10.1111/tsq.12059

Israelsen, C. L., \& Hatch, S. (2005). Proactive research: Where art thou? Financial Counseling and Planning, 16(2), 91-96. Retrieved from http://ovidsp.ovid. com/ovidweb.cgi? $\mathrm{T}=\mathrm{JS} \& \mathrm{PAGE}=$ reference $\& \mathrm{D}=$ psyc $4 \&$ NEWS=N\&AN=2006-11386-007

Kahneman, D., Diener, E., \& Schwarz, N. (Eds.). (1999). Well-being: Foundation of hedonic psychology. New York, NY: Russell Sage Foundation.

Kahneman, D., Krueger, A. B., Schkade, D., Schwarz, N., \& Stone, A. A. (2006). Would you be happier if you were richer? A focusing illusion. Science, 312(5782), 1908 1910. doi:10.1126/science. 1127891

Keefe, J. M., \& Fancey, P. (1997). Financial compensation or home help services: Examining differences among program recipients. Canadian Journal on Aging/La Revue Canadienne Du Vieillissement, 16(2), 254-278. doi:10.1017/S0714980800014343

Kerkmann, B. C., Lee, T. R., Lown, J. M., \& Allgood, S. M. (2000). Financial management, financial problems and marital satisfaction among recently married university students. Journal of Financial Counseling \& Planning, 11(2), 55-65.

Kinnunen, U., \& Pulkkinen, L. (1998). Linking economic stress to marital quality among Finnish marital couples. Journal of Family Issues, 19(6), 705-724. doi:10.1177/019251398019006003

Kwon, H.-K., Rueter, M. A., Lee, M.-S., Koh, S., \& Ok, S. W. (2003, May). Marital relationships following the Korean economic crisis: Applying the family stress model. Journal of Marriage and Family, 65, 316-325. doi:10.1111/j.1741-3737.2003. 00316.x
Lee, J. M., \& Hanna, S. D. (2015). Savings goals and saving behavior from a perspective of Maslow's Hierarchy of Needs. Journal of Financial Counseling \& Planning, 26(2), 129-147. doi:10.1891/1052-3073.26.2.129

Li, T., \& Fung, H. H. (2011). The dynamic goal theory of marital satisfaction. Review of General Psychology, 15(3), 246-254. doi:10.1037/a0024694

Litwin, H., \& Meir, A. (2013). Financial worry among older people: Who worries and why? Journal of Aging Studies, 27(2), 113-120. doi:10.1016/j.jaging.2012.12.003

Maslow, A. H. (1943). A theory of human motivation. Psychological Review, 50, 370-396. doi:10.1037/ h0054346

Maslow, A. H. (1971). The farther reaches of the human nature. New York, NY: Viking Press.

McKee-Ryan, F. M., Song, Z., Wanberg, C. R., \& Kinicki, A. J. (2005). Psychological and physical well-being during unemployment: A meta-analytic study. Journal of Applied Psychology, 90(1), 53-76. doi:10.1037/0021-9010.90.1.53

Muntaner, C., Eaton, W. W., Diala, C., Kessler, R. C., \& Sorlie, P. D. (1998). Social class, assets, organizational control and the prevalence of common groups of psychiatric disorders. Social Science \& Medicine, 47(12), 2043-2053. doi:10.1016/S0277-9536(98)00309-8

Nichols, A., \& Zimmerman, S. (2008). Measuring trends in income variability. Washington, DC: Urban Institute.

O'Neill, B., Prawitz, A. D., Sorhaindo, B., Kim, J., \& Garman, E. T. (2006). Changes in health, negative financial events, and financial distress/financial wellbeing for debt management program clients. Journal of Financial Counseling and Planning, 17(2), 4663. doi:10.1037/t60365-000. Retrieved from https:// ssrn.com/abstract $=2232121$

O’Neill, B., Sorhaindo, B., Xiao, J. J., \& Garman, E. T. (2005). Financially distressed consumers: Their financial practices, financial well-being, and health. Journal of Financial Counseling \& Planning, 16(1), 73-87. doi:10.1016/j.envpol.2011.10.001

Paul, C., Mason, W. M., McCaffrey, D., \& Fox, S. A. (2008). A cautionary case study of approaches to the treatment of missing data. Statistical Methods and Applications, 17(3), 351-372. doi:10.1007/s10260-007-0090-4

Proulx, C. M., Helms, H. M., \& Buehler, C. (2007). Marital quality and personal well-being A meta-analysis. Journal of Marriage and Family, 69(3), 576-593. doi:10.1111/j.1741-3737.2007.00393.x 
Sherraden, M. (1991). Assets and the poor: New American welfare policy (1st ed.). Armonk, NY: M.E. Sharpe.

Sherraden, M. S., McBride, A. M., \& Beverly, S. G. (2010). Striving to save: Creating policies for financial security of low-income families. Ann Arbor, MI: University of Michigan Press.

Shim, S., Xiao, J. J., Barber, B. L., \& Lyons, A. C. (2009). Pathways to life success: A conceptual model of financial well-being for young adults. Journal of Applied Developmental Psychology, 30(6), 708-723. doi:10.1016/j.appdev.2009.02.003

Stack, S., \& Eshleman, J. R. (1998). Marital status and happiness: A 17-nation study. Journal of Marriage and Family, 60(2), 527-536. doi:10.2307/353867

Stevenson, B., \& Wolfers, J. (2008). Economic growth and subjective well-being: Reassessing the Easterlin Paradox. Brookings Papers on Economic Activity, 87, 1-87. doi:10.1353/eca.0.0001

Stevenson, B., \& Wolfers, J. (2013). Subjective wellbeing and income: Is there any evidence of satiation? American Economic Review, 103(3), 598-604. doi:10.1257/aer.103.3.598

Veenhoven, R., \& Vergunst, F. (2014). The Easterlin illusion: Economic growth does go with greater happiness. International Journal of Happiness and Development, 2(4), 311-351. doi:10.1504/IJHD.2014.066115
Xiao, J. J., \& Noring, F. E. (1994). Perceived saving motives and hierarchical financial needs. Financial Counseling and Planning, 5(1), 25-45.

Xiao, J. J., Sorhaindo, B., \& Garman, E. T. (2006). Financial behaviours of consumers in credit counselling. International Journal of Consumer Studies, 30(2), 108-121. doi:10.1111/j.1470-6431.2005.00455.x

Xiao, J. J., Tang, C., \& Shim, S. (2009). Acting for happiness: Financial behavior and life satisfaction of college students. Social Indicators Research, 92(1), 53-68. doi:10.1007/s11205-008-9288-6

Yadama, G. N., \& Pandey, S. (1995). Effect of sample size on goodness-fit of-fit indices in structural equation models. Journal of Social Service Research, 20(3-4), 49-70. doi:10.1300/J079v20n03_03

Zhao, X., Lynch, J. G., \& Chen, Q. (2010). Reconsidering Baron and Kenny: Myths and truths about mediation analysis. Journal of Consumer Research, 37(2), 197206. doi:10.1086/651257

Zimmerman, F. J., \& Katon, W. (2005). Socioeconomic status, depression disparities, and financial strain: What lies behind the income-depression relationship? Health Economics, 14(12), 1197-1215. doi:10.1002/hec.1011

Disclosure. The authors have no relevant financial interest or affiliations with any commercial interests related to the subjects discussed within this article. 